\section{Yasuní oil plans call for vigilance}

Ecuador's President Rafael Correa announced last month that development would begin in the eastern edge of the world's most biodiverse area, the Yasuní Biosphere Reserve. Despite his innovative 2007 proposal to leave oil deposits there untouched, insufficient offsetting funds materialized. Poverty applies the greatest pressure to nature, Correa declared.

Correa promised that the latest technologies will be used to minimize direct impacts and to avoid indirect ones altogether. He pointed out that sacrificing the sector, known as the ITT block, will affect "less than $0.1 \%$ " of the reserve's area and generate a US\$18.2-billion pay-off.

The devastating history of oil extraction in other parts of Ecuador might prompt scepticism about this figure, but it could be realized if offshore methods are faithfully incorporated and no new access roads are built. Everything possible must be done to preserve this unique piece of Amazonia, which contains more than 100,000 species in each hectare of intact forest.

However, contracts between the government and an operator for the development of an oil-concession area can be undermined by rapid advances in technology, so that even the most visionary operations end up using obsolete methods and equipment. Sensitive and biodiverse areas such as Yasuní need to retain new technologies throughout any extraction operation.

Kelly Swing Tiputini Biodiversity Station, University of San Francisco de Quito, Ecuador. kswing@usfq.edu.ec

\section{Ban resistant strains from food chain}

No reliable treatment is available for humans infected with carbapenem-resistant
Enterobacteriaceae (CREs; see Nature 499, 394-396; 2013).

Because these antibiotic-

resistant bacterial pathogens are already entering the food chain (J. Fisher et al. J. Antimicrob. Chemother. 68, 478-480; 2013) and can be transmitted through oral consumption (A. R. Manges and J. R. Johnson Clin. Infect. Dis. 55, 712-719; 2012), we call for a zero-tolerance ruling on CREs in retail food to stop the situation from getting out of control.

It was estimated that in 2007 more than 1,500 people in Europe died from an invasive infection caused by a strain of Escherichia coli that was resistant to third-generation cephalosporins and originated in poultry (P. Collignon et al. Emerg. Infect Dis. 19, 1339-1340; 2013). Mortality from CREs is expected to be much higher if it spreads in poultry on a comparable scale.

Current regulations on antimicrobial usage are largely ineffective - mainly because they operate only at a national level, whereas antimicrobial sales and consumption are global. An international ban on the sale of food items containing CREs could force imported and locally produced food to meet the same standards.

Such a ban would also comply with the guidelines of the Codex Alimentarius Commission, which sets international food standards under the World Trade Organization's Agreement on the Application of Sanitary and Phytosanitary Measures.

Given that CREs can be detected rapidly and reliably in culture-based or molecular assays, routine testing of meat products should be achievable. We urge politicians and decisionmakers to protect public health by acting promptly, before the problem becomes widespread and unmanageable.

Jan Kluytmans* VU University Medical Center, Amsterdam, the Netherlands.

jankluytmans@gmail.com
${ }^{\star}$ On behalf of 8 co-signatories (see go.nature.com/qahy $4 b$ for full list).

\section{E-learning booster in developing world}

Online courses and virtual education laboratories are proving valuable in the resource-limited developing world, where there are many more potential learners than can be accommodated by the pool of experienced classroom teachers and institutions offering scientific education (see Nature 495, 160-163; 2013 and Nature 499, 268-270; 2013).

India has developed its own innovative examples of freely available e-learning resources. Scientific-education materials, such as those supplied by the Sakshat Virtual Labs and the National Programme on Technology Enhanced Learning, are also available to a global audience (S. Ray et al. PLoS Biol. 10, e1001353; 2012).

In developing countries, the anticipated benefits of such resources extend beyond distance learning. Science and technology skills can fuel a knowledge-driven economy, narrowing a country's poverty gap and leading to national prosperity that is embedded in sustainable practices.

Sanjeeva Srivastava ${ }^{\star}$ Indian Institute of Technology Bombay, Mumbai, India.

sanjeeva@iitb.ac.in ${ }^{*}$ On behalf of 7 co-signatories (see go.nature.com/9zknx1 for full list).

\section{Boycott challenges research tactics}

Italy's National Agency for the Evaluation of the University System and Research (ANVUR) has released its evaluation report for the period 2004-10 (see Nature doi.org/nrx). The country's largest publicly funded research organization, the National Research Council (CNR), came unexpectedly low in this ranking - despite its impressive record in basic and applied research products (see go.nature.com/kv2ipo; in Italian). In our view, this is a result of a boycott of the evaluation process by a group of CNR researchers.

During ANVUR's evaluation, a 'reform' under Silvio Berlusconi's government centralized decisions within the CNR by a board of five government nominees, excluding CNR researcher representatives making the CNR the only public research organization in Italy without any researchers on its governing board.

In protest, some $15 \%$ of CNR researchers decided not to submit their publications for evaluation by ANVUR. Because missing products score negatively, the effect of the boycott was amplified and seems to have affected the CNR's ranking.

In a press release, the CNR's chairman, Luigi Nicolais, attributed the council's low ranking to bias in the ANVUR criteria, indicating that the CNR should help Italy's growth and support its enterprises and public administrations, and that these activities should in future be evaluated alongside scientific publications. Most CNR scientists would object to this, however, as they see research as their principal task.

Not all CNR researchers (including ourselves) agreed about the strategic value of the boycott, but it was a last stand for internal democracy, representation and transparency in decision-making at the CNR. To our knowledge, these issues remain unresolved.

Umberto Amato CNR Institute for Applied Mathematics "Mauro Picone", Naples, Italy. Patrizia Lavia Institute of Molecular Biology and Pathology, Rome, Italy. patrizia.lavia@uniroma1.it Vito Mocella Institute for Microelectronics and Microsystems, Naples, Italy. 